\title{
The burden of hypertension in KwaZulu-Natal Province, South Africa: A 6-year perspective
}

\author{
S Pillay, ${ }^{1}$ PhD, FCP (SA), MMed, MB ChB; D Pillay, ${ }^{2}$ scholar; R S Pillay, ${ }^{3}$ scholar \\ ${ }^{1}$ Department of Internal Medicine, King Edward VIII Hospital and Nelson R Mandela School of Clinical Medicine, University of KwaZulu-Natal, \\ Durban, South Africa \\ 2 Star College, Durban, South Africa \\ ${ }^{3}$ Clifton College, Durban, South Africa
}

Corresponding author: S Pillay (drspillay@iafrica.com)

Background. Hypertension (HPT) and its complications continue to pose a global threat and contribute to premature mortality worldwide. The adverse interactions between HPT, obesity and COVID-19 are currently being witnessed globally and represent a collision of pandemics. Understanding the burden that this non-communicable disease (NCD) poses in KwaZulu-Natal (KZN) Province, South Africa (SA), would help in developing improved public healthcare strategies.

Objectives. To describe the burden of HPT in all the districts of KZN over a 6-year period.

Methods. HPT data are routinely collected from all KZN public health facilities (both clinics and hospitals) as part of the District Health Information System (DHIS). In this retrospective study, we accessed HPT records from the DHIS over a period of 6 years (2014 - 2019, inclusive). Data collected included the number of patients screened, diagnosed and initiated on therapy for HPT, together with the number of obese patients.

Results. The slopes for HPT screening were positive at both clinics and hospitals in KZN (considerably more at clinics than hospitals, with a difference in elevations of slopes of $p<0.001$ ), with a significantly greater percentage of the population having been screened at rural clinics than at hospitals (difference in elevation of slopes $p<0.001)$. A significantly greater number of patients aged $<40$ years $(p<0.001)$ were being screened for HPT at clinics than at hospitals $(2017 / 18,2018 / 19,2019 / 20)$, while hospitals screened considerably more patients aged $\geq 40$ years in 2017 - 2018 ( $p<0.001$ ). The numbers of new hypertensives diagnosed and having treatment initiated were on an upward slope at both clinics and hospitals, with clinics having a greater elevation of slope than hospitals $(p<0.001)$, irrespective of patient age. A significantly greater number of patients aged $\geq 40$ years $(p<0.05)$ were diagnosed with HPT at both clinics and hospitals in KZN $(2017 / 18$, 2018/19, 2019/20). KZN clinics remained the first port of call for known hypertensives throughout the study period. Obesity was prevalent at both clinic and hospital level, although figures were significantly higher at clinics. Over $80 \%$ of the obesity burden was carried by the rural clinics and hospitals.

Conclusions. Screening, diagnosis, treatment initiation and chronic management of HPT occur mainly at rural clinic level. The SA government needs to heed these findings and redirect resources (staffing and equipment) to this level. The prevalence of obesity was highest at rural healthcare facilities (clinics more than hospitals). More needs to be done to combat the obesity pandemic if we are to win the battle against NCDs (HPT and diabetes mellitus). A significant number of patients aged $<40$ years are being screened for HPT, which bodes well for the province, as early diagnosis and treatment of HPT are vital to prevent complications.

S Afr Med J 2021;111(2):159-165. https://doi.org/10.7196/SAMJ.2021.v111i2.15056

Hypertension (HPT) is regarded as one of the most important cardiovascular risk factors globally, estimated to affect more than one billion people. Globally, non-communicable diseases (NCDs) are responsible for $70 \%$ of deaths, the majority from cardiovascular diseases such as cerebrovascular disease and myocardial infarction. ${ }^{[1,2]}$ HPT remains a major contributor to premature mortality globally. ${ }^{[3,4]}$ It is estimated that $>80 \%$ of the burden associated with HPT is now carried by low- and middle-income countries, with Africa having the highest prevalence of HPT among adults worldwide. ${ }^{[5]}$ Elevated blood pressure and HPT account for more deaths globally than any of the other cardiovascular risk factors (smoking, obesity and dyslipidaemia). ${ }^{[6]}$

The current COVID-19 pandemic highlights the critical interaction between communicable diseases and NCDs worldwide. Several studies have recently demonstrated that HPT, obesity and diabetes mellitus (DM) are important comorbidities associated with increased mortality risk in patients with COVID-19 infection..$^{[7-10]}$ The prevalence of NCDs in patients with COVID-19 infection has been shown to range from $15 \%$ to $33 \%$ for HPT and from $8.4 \%$ to $20 \%$ for DM. ${ }^{[11-15]}$ Wang et al. ${ }^{[11]}$ and Zhou et al. ${ }^{[12]}$ showed that the prevalence of severe COVID-19 infection was $58 \%$ and $48 \%$, respectively, in patients with $\mathrm{HPT}$ and $22 \%$ and $31 \%$, respectively, in patients with DM. Another study showed that the presence of HPT in a COVID-19-infected patient increased the odds of mortality by a factor of three. ${ }^{[16,17]}$ In addition, various studies have shown that obesity is an independent risk factor for severe COVID-19 infection. ${ }^{[18,19]}$

Results from the South African National and Nutrition Examination Study demonstrated that $35.1 \%$ of individuals $(35.2 \%$ of males and $34.7 \%$ of females) aged $>15$ years in South Africa (SA) were hypertensive, ${ }^{[20]}$ and that $91.1 \%$ of the SA hypertensive population were unscreened, undiagnosed, untreated or uncontrolled. A mere $8.9 \%$ of the total SA hypertensive population was shown to be 
controlled. In contrast, estimates from the USA indicated that $29.1 \%$ of their population were hypertensive, with over half of these patients (52\%) being classified as controlled. ${ }^{[21]}$

SA currently has the highest prevalence of HIV infection globally (13.5\%). ${ }^{[22]}$ The combination of HIV/tuberculosis (TB) and NCDs in the form of HPT and DM poses a massive problem for both individual patients and the country. Brennan et al. ${ }^{[23]}$ showed that HPT was common among patients who were HIV-infected, those who were on antiretroviral therapy, and those who were overweight or obese.

SA has the highest prevalence of HPT in sub-Saharan Africa (SSA), and also the greatest number of patients whose blood pressure is suboptimally controlled despite being on treatment. ${ }^{[2]}$ Rapid urbanisation has been postulated as one of the reasons for the high prevalence of HPT in SA. ${ }^{[25]}$ Addo et al. ${ }^{[26]}$ in a systematic review of 25 studies conducted in SSA, concluded that the majority of patients with HPT lived in urban areas. The latest Statistics South Africa survey showed that two-thirds of the SA population live in urbanised areas. ${ }^{[22]} \mathrm{HPT}$ is not exclusively limited to urban areas, as Ntuli et al..$^{[27]}$ found that there is also a high prevalence of HPT in rural patients. They suggested that prevention strategies need to be developed for rural areas as much as for urban ones. It must also be noted that HPT in black African patients is generally more severe, and often more resistant to therapy, than that in other ethnic groups. ${ }^{[26,28]}$

Added to this cauldron of communicable diseases and NCDs, SA has the highest rate of obesity in SSA. ${ }^{[22]}$ Obesity is known to be one of the causes of HPT. ${ }^{[29,30]}$ Berry et al. ${ }^{[20]}$ showed that the prevalence of HPT was highest in patients with higher body mass indices (BMIs), highlighting the fact that weight is a risk factor for development of HPT. Harris et al. ${ }^{[30]}$ found that the odds of developing HPT were much higher (1.7 - 3.4 times) in obese compared with lean individuals. Importantly, it has also been shown that weight loss results in a drop in blood pressure. ${ }^{[31]}$ Majane et al. ${ }^{[32]}$ showed in black African patients that for every $15 \mathrm{~cm}$ increase in waist circumference there was an increase in systolic and diastolic blood pressure of $\sim 3 \mathrm{mmHg}$. They also stated that HPT and obesity work synergistically in increasing cardiovascular damage. The Heart of Soweto study found that obesity was the most important aetiological factor associated with hypertensive heart disease. ${ }^{[33]}$ Obesity has been shown to be associated with living in urban areas. ${ }^{[34]}$ Being obese also carries with it the risk of developing another heavyweight NCD in the form of insulin resistance and DM. ${ }^{[35]}$

The World Health Organization has stated that the burden of NCDs in SA is two to three times higher than that in developed countries. ${ }^{[36]}$ SA's NCD burden is on an increasing trend in rural areas as well. ${ }^{[37]}$ It is estimated that NCDs (DM, heart disease and stroke) cost the SA government $\sim$ USD1.88 billion between 2006 and 2015. ${ }^{[38]}$ Kenge and Mchiza ${ }^{[39]}$ pointed out that NCD costs are both tangible (work absenteeism, decreased productivity and time losses) and intangible (decreased quality of life, pain and suffering) in nature.

In 2011, together with many other countries, SA agreed to introduce the Global Action Plan, which aimed to prevent and control NCDs and decrease premature NCD mortality by at least one-third. ${ }^{[1]}$

\section{Objectives}

To describe the burden of HPT in all the districts of KwaZulu-Natal (KZN) Province, SA, over a 6-year period.

\section{Methods}

KZN is the second most populated province in SA and has a high burden of both communicable diseases and NCDs. ${ }^{[10]} \mathrm{KZN}$ is divided into one metropolitan municipality (eThekwini) and 10 district municipalities, each having healthcare facilities ranging from clinics to hospital level.

HPT data are collected routinely from all public health facilities in KZN, as part of the District Health Information System (DHIS). The data are then aggregated at facility level, and no individual patient data are used. The data are managed by the Data Management Unit of the KZN Department of Health, which makes them available on request.

In this retrospective study, we accessed records from the DHIS over a period of 6 years (2014 - 2019, inclusive).

\section{Data collection}

After ethics approval for the study had been obtained from the local ethics review committee (Biomedical Research and Ethics Committee, ref. no. BREC 1266/2020) and the KZN Department of Health, data were accessed from the DHIS records.

For the purposes of this study, the following indicators were analysed for each district of KZN:

- For the time periods $2014 / 15,2015 / 16$ and $2016 / 17$, the following DHIS data elements were analysed for all provincial clinics and hospitals:

- number of clients screened for HPT

- number of defaulters

- number of patients who were started on antihypertensive medications.

The data elements collected for HPT were modified by the DHIS in 2017.

- For the time periods 2017/18, 2018/19 and 2019/20, the following DHIS data elements were analysed for all provincial clinics and hospitals:

- number of patients aged $<40$ years screened for HPT

- number of patients aged $\geq 40$ years of age screened for HPT

- number of new HPT cases in patients aged $\geq 40$ years

- number of new HPT cases in patients aged $<40$ years

- number of visits by patients with known HPT

- number of patients with BMI $>30 \mathrm{~kg} / \mathrm{m}^{2}$.

The location of the district was classified as urban or rural. Urban areas comprised urban and semi-urban settings, while the term rural described rural and semi-rural settings.

\section{Statistical analysis}

The data were interrogated to assess the current burden of HPT in KZN using simple descriptive statistics. The weighted means test was used to calculate statistical significance. A $p$-value $<0.05$ was regarded as statistically significant. A comparison in terms of the rates per 100000 population was done using the slopes and elevations test.

\section{Results}

Fig. 1 illustrates the overall HPT screening pattern for clinics and hospitals at all public healthcare facilities in KZN between 2015 and 2020. No significant difference in the slopes of number of patients screened for HPT at clinic v. hospital level was found $(p=0.971)$; however, there was a significant difference between these slopes in terms of elevation $(p<0.001)$. 
Further subdivision of patients screened for HPT into those aged $<40$ years and $\geq 40$ years confirmed that the majority of HPT screening in KZN is being conducted at clinic level, irrespective of patient age (Figs 2 and 3).

Table 1 shows that clinics were screening a significantly higher number of patients aged $<40$ years for HPT than older patients. However, this trend was not seen at hospital level, where considerably more patients aged $\geq 40$ years were screened in the 2017/18 period.

Fig. 4 illustrates the total number of new hypertensives diagnosed at the various KZN public healthcare facilities for the period 2014 - 2020. No significant difference in the slopes of number of patients diagnosed with HPT at clinic v. hospital level was found $(p=0.781$ ), but there was a significant difference in elevation between these slopes $(p<0.001)$.

Figs 5 and 6 demonstrate that the majority of new patients with HPT, irrespective of age, were diagnosed and had their treatment initiated at clinic level.

A considerably greater number of patients aged $\geq 40$ years were diagnosed with HPT compared with patients $<40$ years of age. This phenomenon was observed at both clinics and hospitals in KZN over the study period (Table 2).

Fig. 7 shows that a greater number of known hypertensive patients had consultations at KZN clinics rather than hospitals over the study period $(p<0.001)$.

Obesity remains a challenge in SSA. The present study showed that obesity was prevalent in both clinic and hospital patients, although to a significantly greater extent in patients visiting clinics rather than hospitals (Fig. 8). The study showed that obesity remains a problem in both rural and urban areas in KZN (Fig. 9).

Further sub-analysis of overall numbers of obese patients per 100000 population per district using a Pareto chart revealed that $>80 \%$ of the obesity burden at both KZN clinics and hospitals occurs outside the urbanised metro municipality (Figs 10 and 11).

Significantly more patients were screened for HPT in rural than in urban areas during the study period (Fig. 12). This trend was similar in both the $<40$ - and $\geq 40$-year age groups. No significant difference in the slopes of number of patients screened for HPT at rural v. urban healthcare settings was found $(p=0.769)$; however, there was a

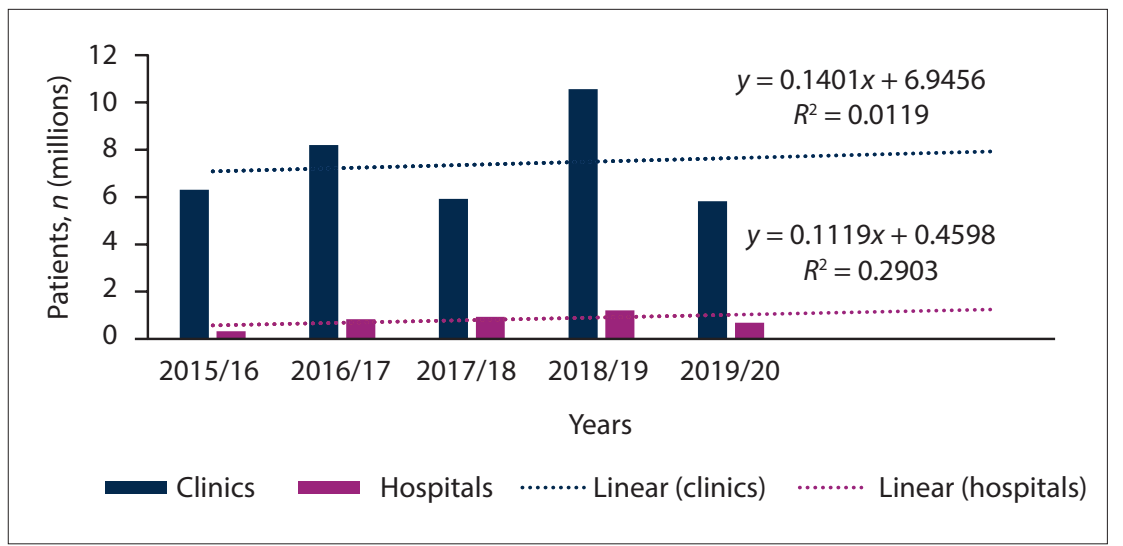

Fig. 1. Overall number of patients screened for hypertension (in millions).

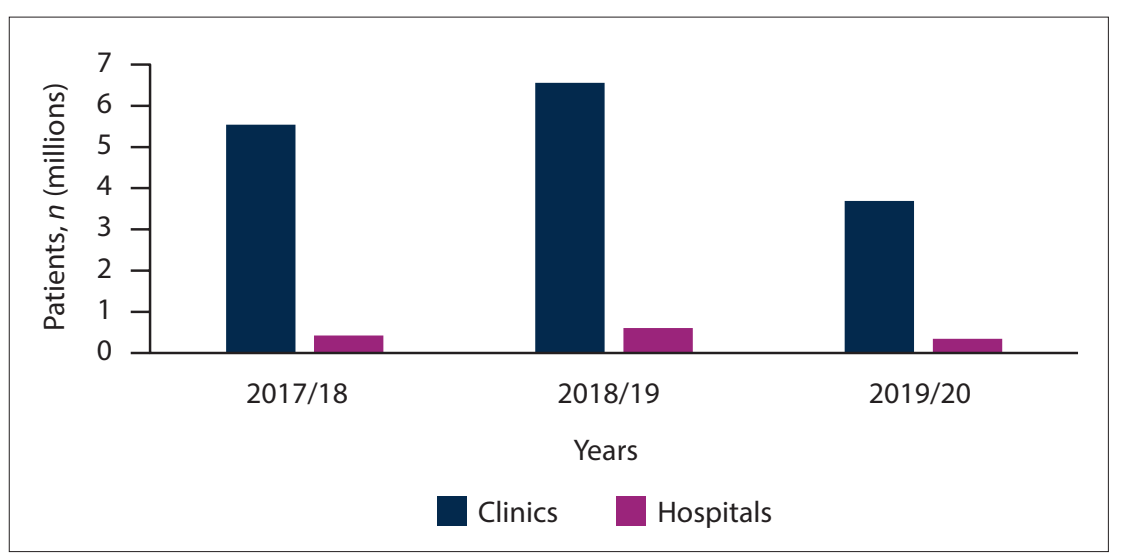

Fig. 2. Number of patients aged $<40$ years screened for hypertension (in millions).

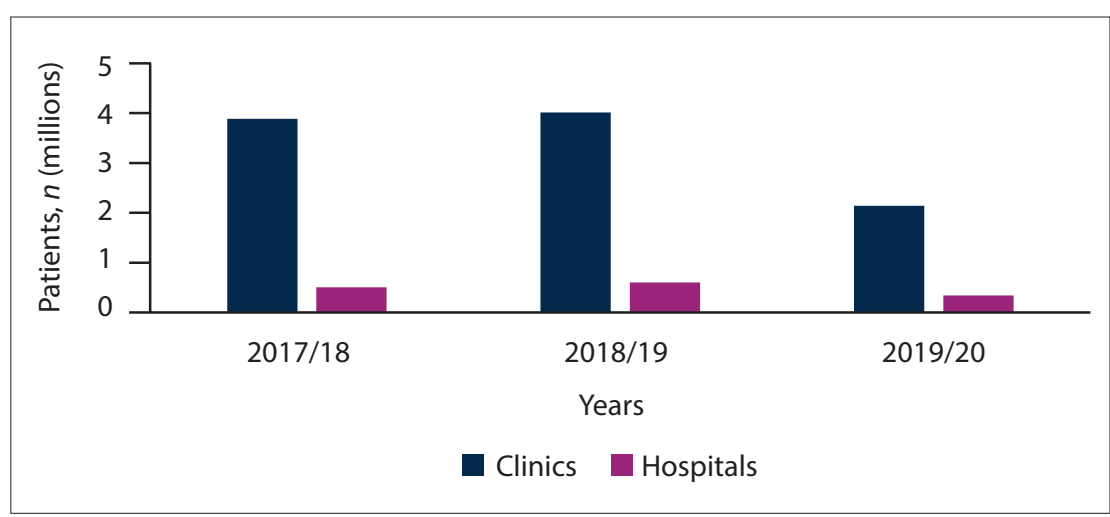

Fig. 3. Number of patients aged $\geq 40$ years screened for hypertension (in millions).

\begin{tabular}{|c|c|c|c|}
\hline & $<40$ years, $n$ & $\geq 40$ years, $n$ & $p$-value \\
\hline \multicolumn{4}{|l|}{ Clinics } \\
\hline 2017/18 & 5538000 & 3884218 & $<0.001$ \\
\hline $2018 / 19$ & 6553364 & 4013218 & $<0.001$ \\
\hline $2019 / 20$ & 3687566 & 2138231 & $<0.001$ \\
\hline \multicolumn{4}{|l|}{ Hospitals } \\
\hline $2017 / 18$ & 423348 & 506456 & $<0.001$ \\
\hline $2018 / 19$ & 607569 & 604948 & 0.452 \\
\hline $2019 / 20$ & 345263 & 341860 & 0.195 \\
\hline
\end{tabular}




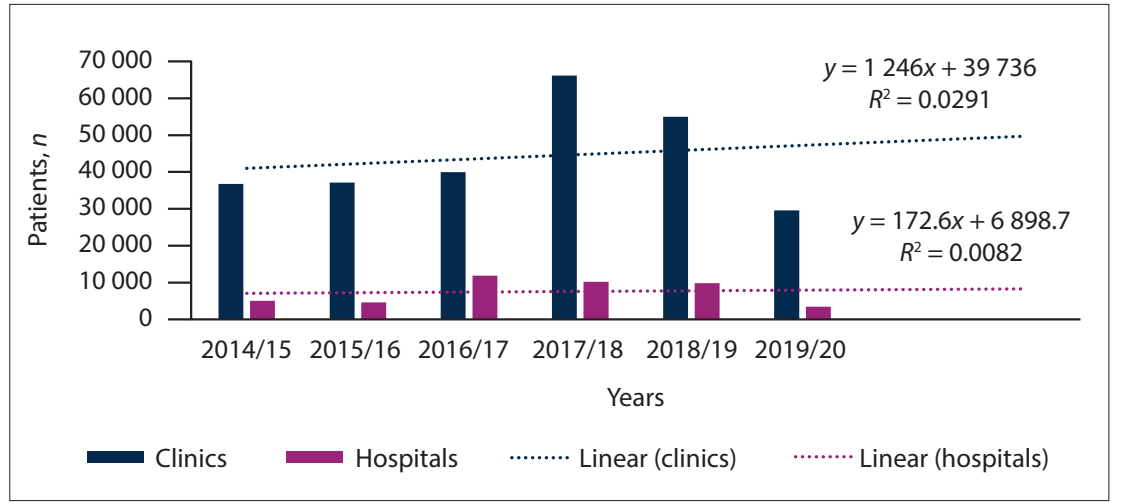

Fig. 4. Number of new patients diagnosed with hypertension and having treatment initiated.

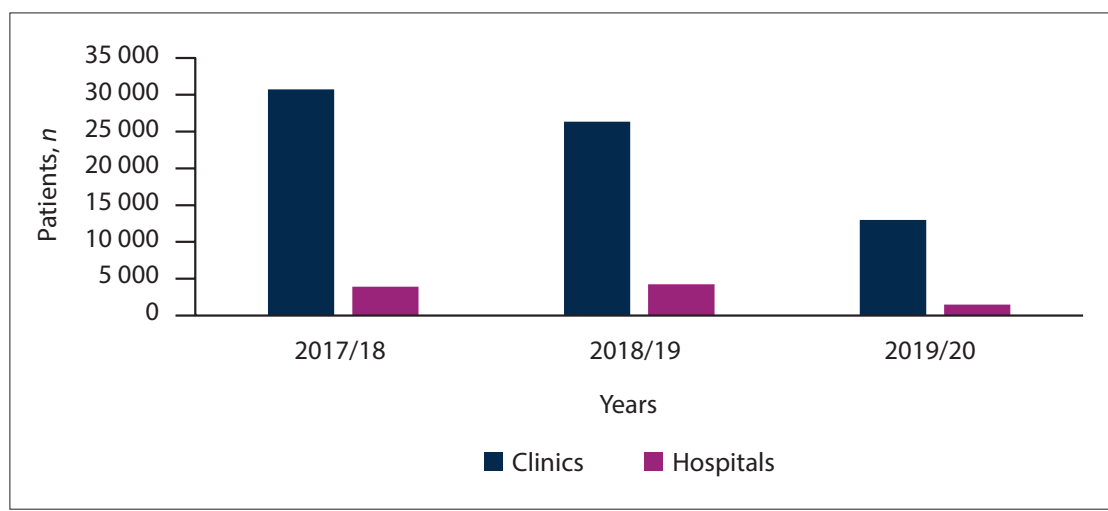

Fig. 5. Number of patients aged $<40$ years initiated on treatment for hypertension.

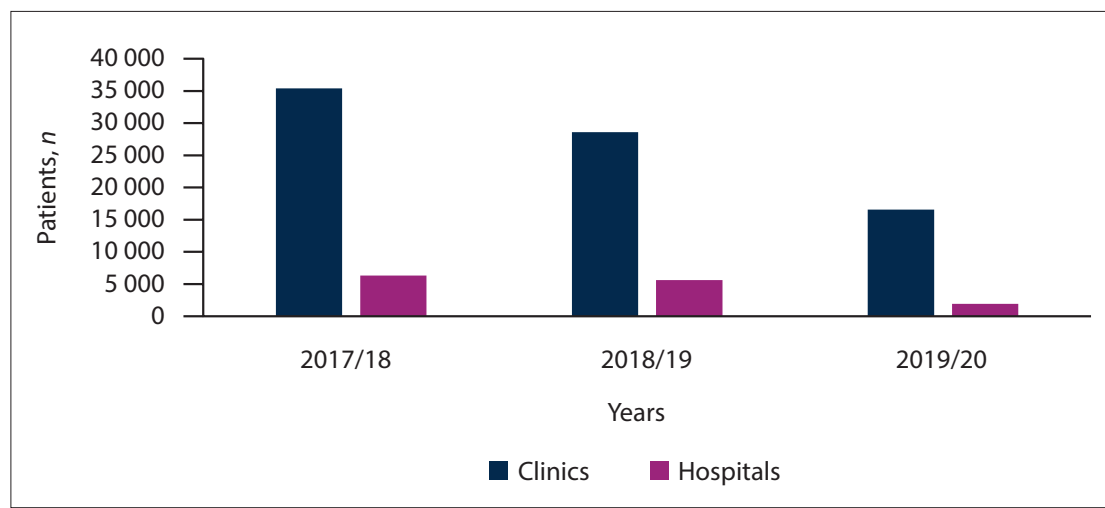

Fig. 6. Number of patients aged $\geq 40$ years initiated on treatment for hypertension.

Table 2. Age distribution of patients diagnosed with hypertension in clinics and hospitals

\begin{tabular}{llll}
\hline & $<40$ years, $\boldsymbol{n}$ & $\mathbf{2 4 0}$ years, $\boldsymbol{n}$ & $\boldsymbol{p}$-value \\
\hline Clinics & & & \\
$2017 / 18$ & 30743 & 35414 & $<0.001$ \\
$2018 / 19$ & 26355 & 28612 & 0.002 \\
$2019 / 20$ & 12987 & 16578 & $<0.001$ \\
Hospitals & & & \\
$2017 / 18$ & 3905 & 6317 & $<0.001$ \\
$2018 / 19$ & 4254 & 5601 & $<0.001$ \\
$2019 / 20$ & 1473 & 1943 & 0.011 \\
& & &
\end{tabular}

significant difference in elevation between these slopes $(p<0.001)$.
A similar trend (rural significantly higher than urban) was noted with regard to the overall number of new hypertensives diagnosed and treated (Fig. 13). No significant difference in the slopes of number of patients diagnosed with HPT at rural v. urban healthcare settings was found ( $p=0.640)$, but a significant difference was noted in elevation between these slopes $(p<0.001)$.

\section{Discussion}

HPT remains a global threat, and this threat is increasingly being highlighted by the current COVID-19 pandemic. Understanding the pattern of this NCD in KZN will allow us to plan effective interventional public health strategies to assist control efforts in a resource-limited developing country.

Our study demonstrates that, appropriately, screening for HPT is taking place at both public healthcare clinics and hospitals. It further reveals that the clinics were performing the bulk of HPT screening compared with hospitals $(p<0.001)$, irrespective of patient age. Interestingly, a significantly greater number of patients aged $<40$ years compared with $\geq 40$ years were being screened for HPT at clinic level $(p<0.001)$. This bodes well for a disease in which early detection and treatment will delay or prevent long-term complications in the form of blindness, myocardial infarction and renal failure, and so decrease the burden on both individual patients and the economy of the country. It makes practical sense to understand that patients who are seen at hospital level for HPT or other comorbidities are generally older in age.

Results of studies relating to urban $\mathrm{v}$. rural distribution of HPT in Africa and SA have been varied. Addo et al., ${ }^{[26]}$ in their systematic analysis of 25 studies conducted in SSA, found that the majority of hypertensive patients lived in urban areas. In contrast, Ntuli et al. ${ }^{[27]}$ found a high prevalence of HPT in rural patients. The present study showed that the majority of new hypertensive patients initiated onto treatment were seen at clinic level, irrespective of patient age. We found, like Ntuli et al. ${ }^{[27]}$ and Groenewald et al. ${ }^{[37]}$ that the majority of patients diagnosed with HPT were rural, over the entire time period and across both the $<40$ - and $\geq 40$ year age groups $(p<0.05)$.

Having identified that the majority of our new hypertensives are rural patients visiting clinics, we need to develop and intensify existing healthcare systems at this level to help minimise the effects of the HPT pandemic. In 2009, Mayosi et al. ${ }^{[40]}$ called for integration and strengthening of healthcare systems, particularly at the primary healthcare level. They also suggested that SA should 


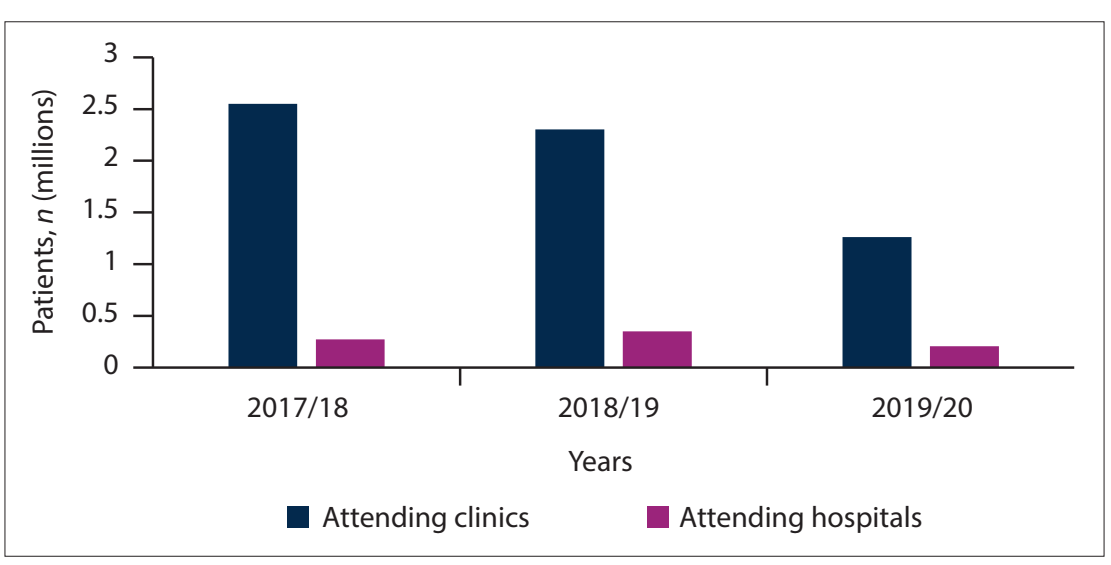

Fig. 7. Number of visits of known hypertensives (in millions).

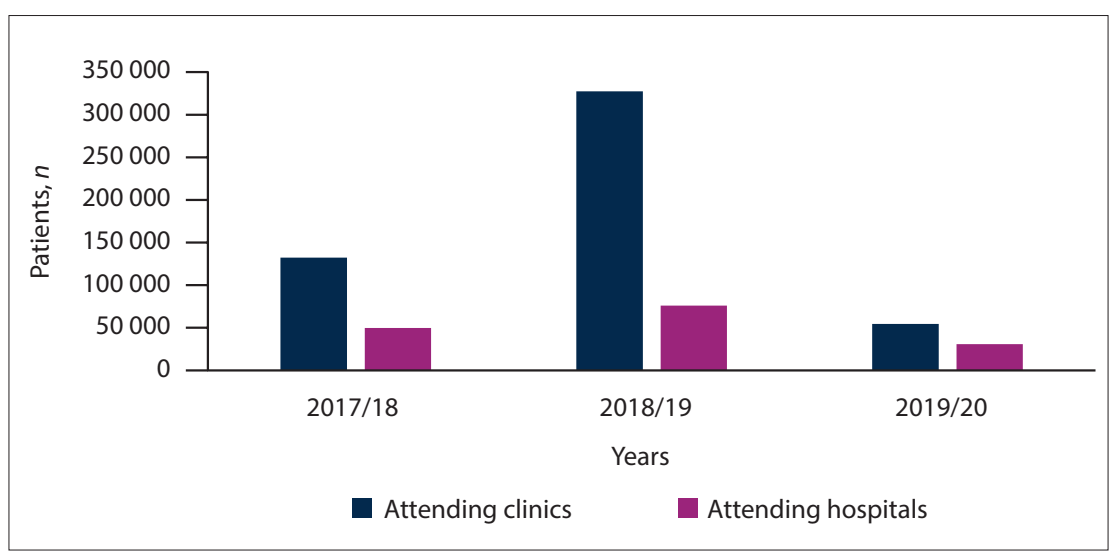

Fig. 8. Number of patients with obesity.

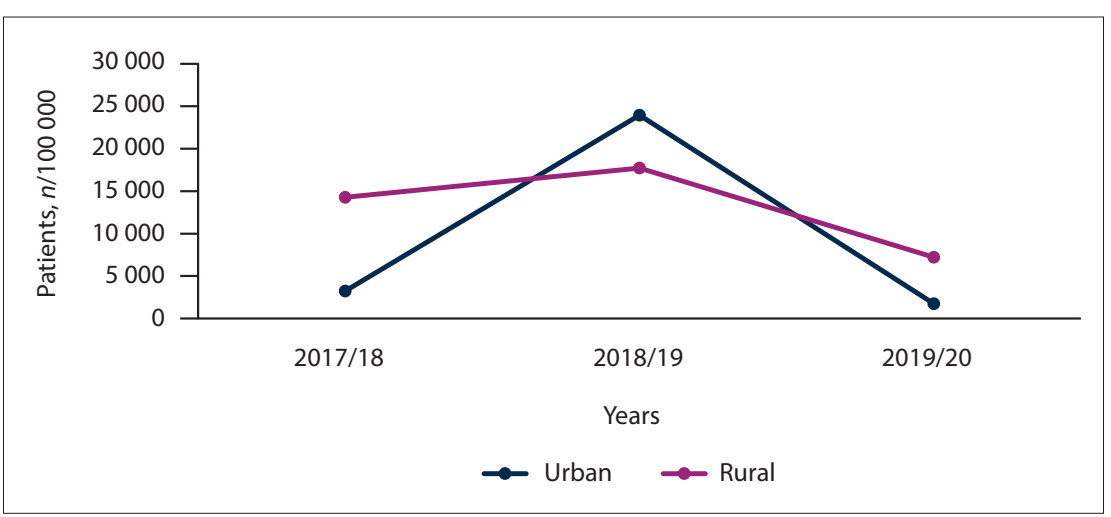

Fig. 9. Number of patients with obesity per 100000 population, urban v. rural.

develop a comprehensive national surveillance system that would be able to determine whether implemented intervention strategies for both communicable diseases and NCDs had real clinical impact. Pillay-van Wyk et $a l .{ }^{[41]}$ showed that while there was a decrease in the number of deaths attributable to HIV and TB in Cape Town between 2009 and 2013, there was a simultaneous increase in the number of deaths attributable to NCDs. They suggested that an integrated national NCD strategy should be put into place to address reversing the effects of HPT and DM. ${ }^{[41]}$ Our study revealed that the majority of patients with known HPT had their consultations at clinic level rather than at hospitals. These results mirror what Pillay et al. ${ }^{[42]}$ found with regard to diagnosis and treatment of DM in KZN. The results of our study support the justification for an integrated and improved primary healthcare system. Resources in the form of both staffing and equipment must be redirected towards this healthcare level as a matter of urgency, as it is where the majority of HPT patients are being diagnosed and have their treatment initiated.

Added to this cauldron of communicable diseases and NCDs, SA has the highest rate of obesity in SSA. ${ }^{[22]}$ Obesity has been shown to be a major aetiological factor in the development of both HPT and DM, two of the most devastating NCDs. ${ }^{[29,30,35]}$ Each of these three NCDs has been implicated in increased morbidity and mortality in patients infected with the coronavirus. ${ }^{[7-10]}$ Results from our study showed that obesity was prevalent in both clinic and hospital hypertensive patients, in both urban and rural areas. Obesity is one of the most important modifiable risk factors for HPT that we must campaign against, in KZN and in SA as a whole, if we are to win the battle against NCDs. Although some studies have shown obesity to be an urban rather than a rural problem, a result of changes to a more westernised diet, we have shown that obesity is a major problem in rural KZN, which carries $>80 \%$ of the obesity burden at both clinic and hospital level. This is extremely worrying, and probably reflects the poverty experienced in these rural areas, with consequent dependence on cheaper energy-dense foods and resultant obesity. Obesity is a precursor to both DM and HPT, two of the major NCDs globally. Urgent intervention strategies need to be developed to target obesity at all levels of healthcare, both in SA and worldwide.

There are currently no regulations in place in SA for annual health screening for asymptomatic adult patients. This lack is possibly a major reason why HPT or elevated blood pressure are only detected late in the course of the disease process in SA. This deficit in the current system can be alleviated by allowing community healthcare workers to do automated blood pressure readings and point-of-care glycosylated haemoglobin testing during their routine home visits, and if necessary, make appropriate referrals to local clinics. This strategy would provide a way to address both of the major NCDs (DM and HPT) simultaneously at community healthcare level, a level at which we and others have shown that most of the diagnosis and treatment of these conditions takes place. ${ }^{[42]}$

\section{Study limitations}

No DHIS data were collected on the number of patients with obesity and HPT. Possible lack of accuracy of data collected by each healthcare facility is also a limitation.

\section{Conclusions}

HPT and its complications remain a global threat. Understanding the burden that this NCD is posing in KZN would help in developing more effective public healthcare strategies. 


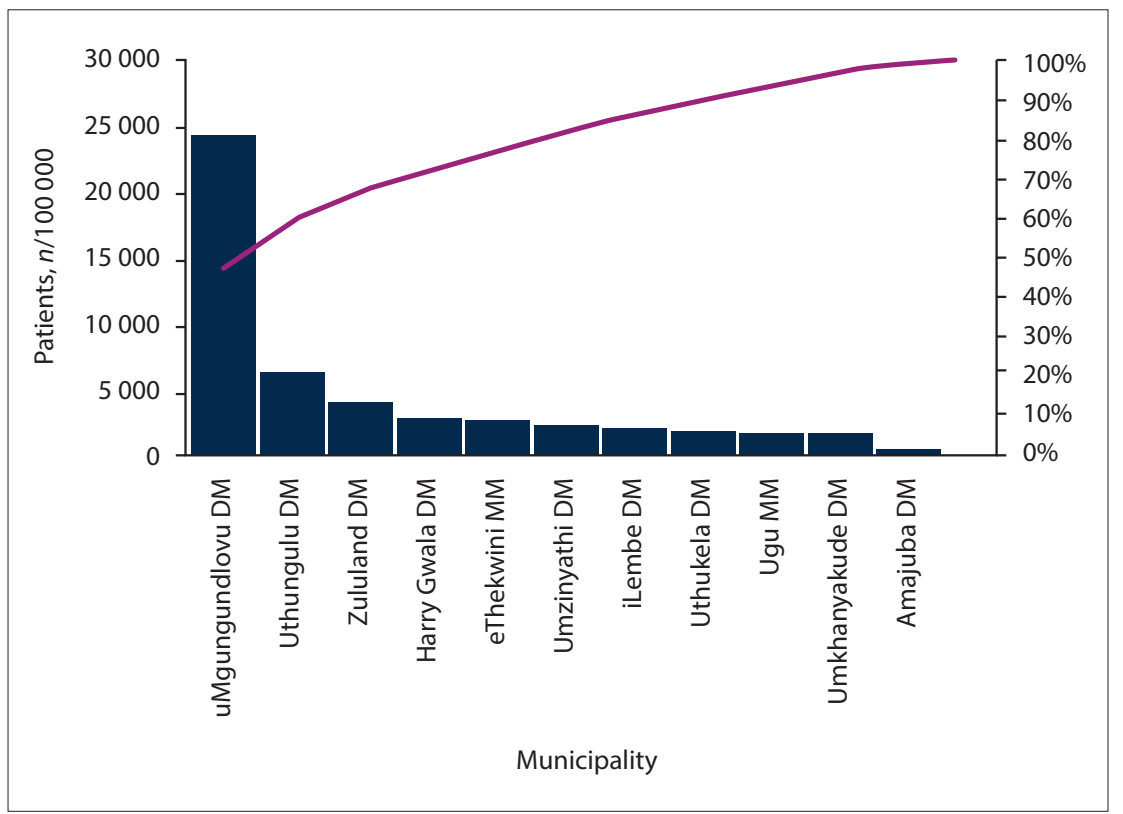

Fig. 10. Pareto chart showing total number of obese patients per 100000 population per district seen in KwaZulu-Natal clinics $(2017 / 18,2018 / 19,2019 / 20)$. (DM = district municipality; MM = metropolitan municipality.)

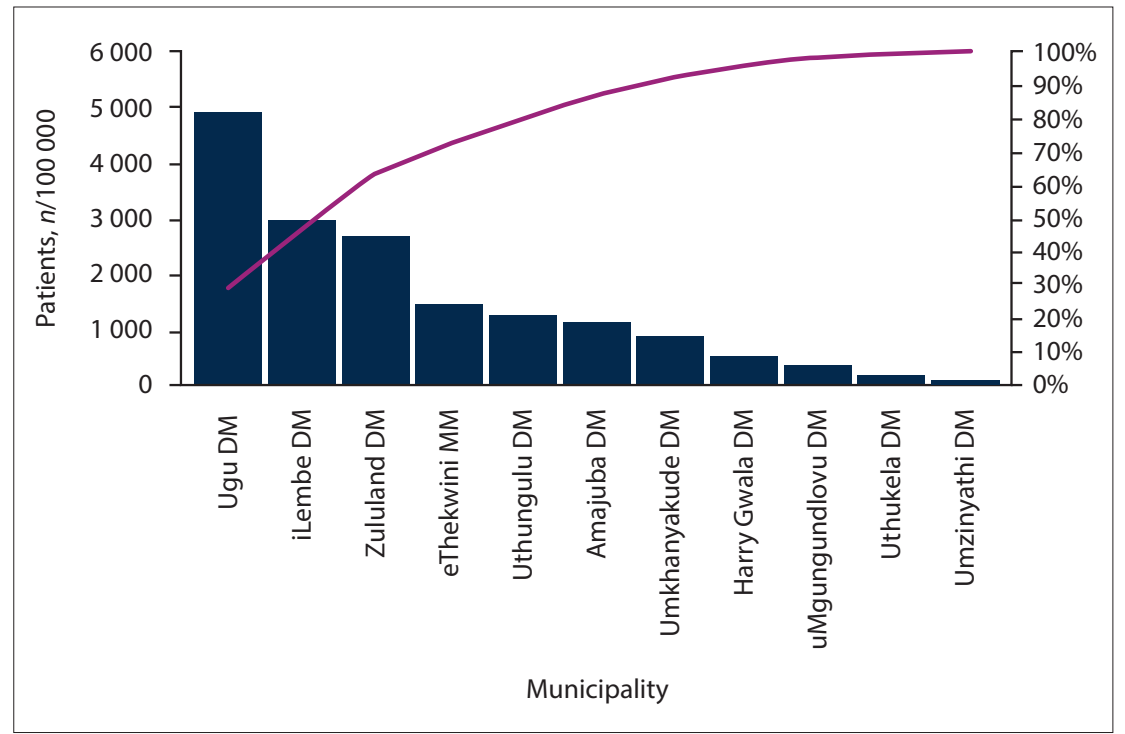

Fig. 11. Pareto chart showing total number of obese patients per 100000 population per district seen in KwaZulu-Natal hospitals (2017/18, 2018/19, 2019/20). (DM = district municipality; $M M=$ metropolitan municipality.)

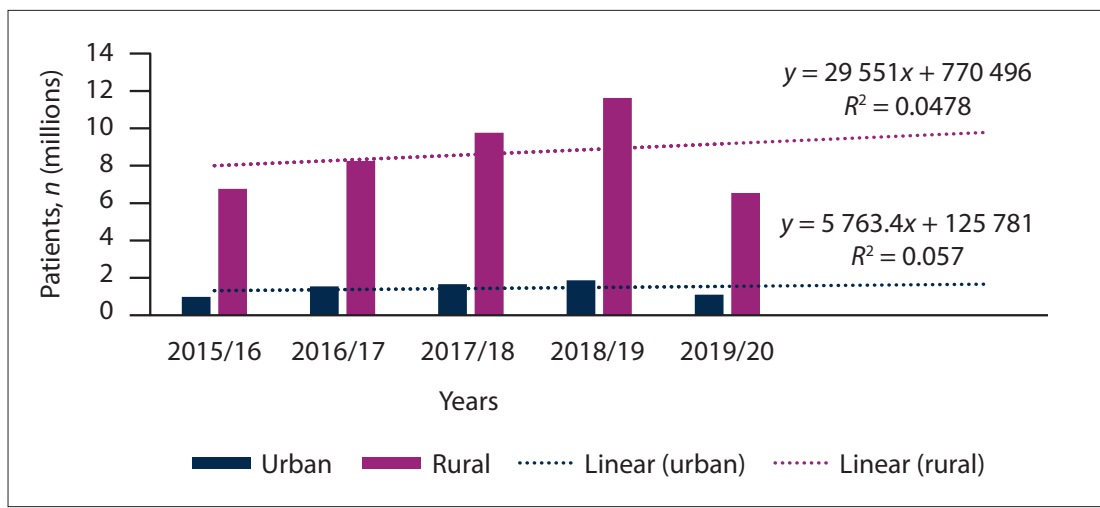

Fig. 12. Overall number of patients screened for hypertension (in millions): urban v. rural.
Screening, diagnosis, initiation of treatment and chronic HPT management are mainly taking place at rural clinic level. The government needs to heed these findings and redirect resources (staffing and equipment) to this level.

Obesity remains a global problem, and KZN has not been spared. We found that obesity was prevalent at both clinic and hospital healthcare level, but mainly in rural healthcare facilities, suggesting that we need to urgently upscale our efforts to curb the obesity pandemic.

\section{Declaration. None.}

Acknowledgements. We thank Mr D Singh for his help on the statistics required for the article. Author contributions. The principal author (SP) made substantial contributions to conception and design of the work, writing of the article and final approval, and agrees to be accountable for all aspects of the research. The co-authors (DP and RP) made substantial contributions to conception of the work, critical review and editing of the draft article and final approval, and agree to be accountable for all aspects of the research.

Funding. None.

Conflicts of interest. None.

1. World Health Organization. Fact sheet: Noncommunicable diseases, 1 June 2018. http://www.who.int/mediacentre/ factsheets/fs355/en/ (accessed 8 April 2020).

2. World Health Organization. Raised blood pressure ( $\mathrm{SBP} \geq 140$ or $\mathrm{DBP} \geq 90$ ), age-standardised (\%) estimates by WHO region. Last updated 16 November 2017. https://apps.who.int/gho/data/node. imr.BP_04?lang=en (accessed 8 April 2020).

3. Lackland DR, Weber MA. Global burden of cardiovascular disease and stroke: Hypertension at the core. Can J Cardiol 2015;31(5):569-571. https://doi.org/10.1016/j.cjca.2015.01.009

4. Poulter NR, Prabhakaran D, Caulfield M. Hypertension. Lancet 2015;386(9995):801-812. https://doi.org/10.1016/S01406736(14)61468-9

5. Islam, SMS, Purnat, TD, Phuong NTA, et al. Non-communicable diseases (NCDs) in developing countries: A symposium report. Glob Health 2014:10:81. https://doi.org/10.1186/s12992-014-0081-9

6. He FJ, McGregor GA. Blood pressure is the most important cause of death and disability in the world. Eur Heart J 2007;9(Suppl B):B23-B28. https://doi.org/10.1093/eurhearti/sum005

7. Guan W, Liang W, Liang H, et al. Comorbidity and its impact on 1590 patients with Covid-19 in China: A nationwide analysis. Eur Respir J 2020;55:2000547. https://doi. org/10.1183/13993003.00547-2020

8. Centers for Disease Control and Prevention. National Diabetes Statistics Report, 2020. Atlanta, Ga.: CDC, US Department of Health and Human Services, 2020. https://www.cdc.gov/diabetes/ $\mathrm{pdfs} /$ data/statistics/national-diabetes-statistics-report.pdf (accessed on 8 April 2020).

9. Onder G, Rezza G, Brusaferro S. Case-fatality, and characteristics of patients dying in relation to COVID-19 in Italy. JAMA 2020:323(18):1775-1776 pation

10. Yang J Zhe Y Y Gou X, et Prove

0. Yang f, Zheng $\mathrm{Y}$ ( novel What cor review and meta-analysis. Int J Infect Dis 2020;94:91-95. https:// doi.org/10.1016/j.ijid.2020.03.017

11. Wang $\mathrm{D}, \mathrm{Hu} \mathrm{B}, \mathrm{Hu} \mathrm{C}$, et al. Clinical characteristics of 138 hospitalised patients with 2019 novel coronavirus-infected pneumonia in Wuhan, China. JAMA 2020;323(18):1775-1776. https://doi.org/10.1001/jama.2020.1585

12. Zhou Y, Vedantham P, Lu K, et al. Protease inhibitors targeting coronavirus and filovirus entry. Antiviral Res 2015;116:76-84. https://doi.org/10.1016/j.antiviral.2015.01.011

13. Guan WJ, Ni ZY, Hu Y, et al. China Medical Treatment Expert Group for COVID-19. Clinical characteristics of coronavirus disease 2019 in China. N Engl J Med 2020:382:1708-1720. https://doi.org/10.1056/NEJMoa2002032 


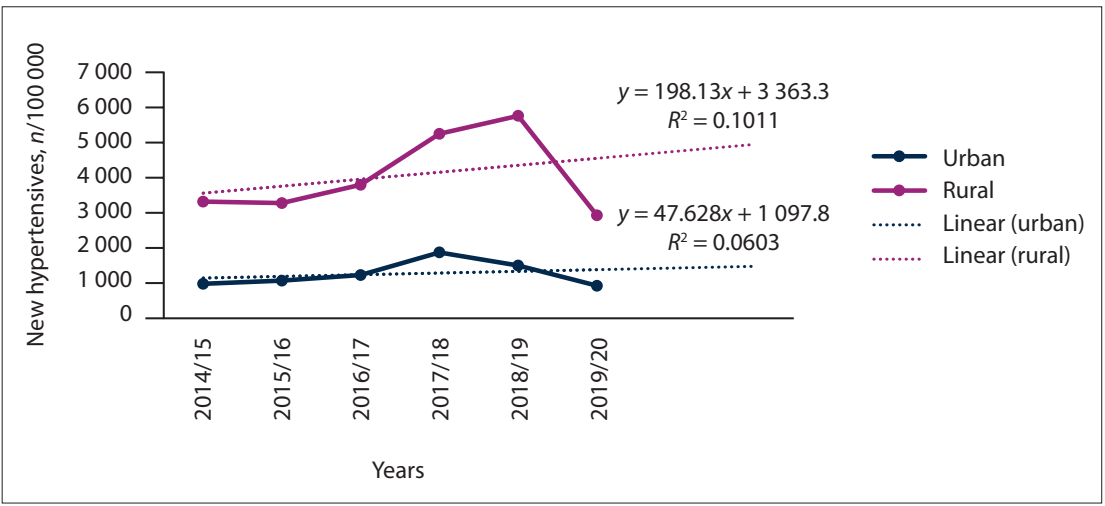

Fig. 13. Overall number of new hypertensives per 100000 population, urban v. rural.

14. Xiachen L, Shunyun X, Muqing Y, et al. Risk factors for severity and mortality in adult COVID-19 inpatients in Wuhan. J Allergy Clin Immunol 2020;146(1):110-118. https://doi.org/10.1016/j. jaci.2020.04.006

15. Huang C, Wang Y, Li X, et al. Clinical features of patients infected with 2019 novel coronavirus in Wuhan, China. Lancet 2020;395(10223):497-506. https://doi.org/10.1016 S0140-6736(20)30183-5

16. Zhou F, Yu T, Du R, et al. Clinical course and risk factors for mortality of adult inpatients with COVID-19 in Wuhan, China: A retrospective cohort study. Lancet 2020;395(10229):1054-1062. A retrospective cohort study. Lancet 2020;395(1025
https://doi.org/10.1016/S0140-6736(20)30566-3

17. Lippi G, Wong J, Henry BM. Hypertension in patients with coronavirus disease 2019 (COVID-19): A pooled analysis. Po Arch Intern Med 2020;130(4);304-309. https://doi.org/10.20452/ pamw.15272

18. Qingxian C, Chen F, Fang L, et al. Obesity and COVID-19 severity in a designated hospital in Shenzhen, China. 2020. Available at SSRN (epub 13 March 2020). https://doi.org/10.2139/ ssrn. 3556658

19. Petrilli CM, Jones SA, Yang J, et al. Factors associated with hospitalisation and critical illness among 4,103 patients with COVID-19 disease in New York City. medRxiv 2020 (epub 11 April 2020). https://doi.org/10.1101/2020.04.08.20057794

20. Berry KM, Parker W-A, Mchiza ZJ, et al. Quantifying unmet need for hypertension care in South Africa through a care cascade: Evidence from the SANHANES, 2011 - 2012. BMJ Glob Health Evidence from the SANHANES, 2011 - 2012. BMJ Glob Health
2017;2(3):e000348. https://doi.org/10.1136/bmjgh-2017-000348

21. Nwanko T, Yoon SS, Burt V, Gu Q. Hypertension among adults

in the United States: National Health and Nutrition Examination
in in the United States: National Health and Nutrition Examination
Survey, 2011 - 2012. NCHS Data Brief 2013:Oct(133):1-8. https:// pubmed.ncbi.nlm.nih.gov/24171916/ (accessed 8 April 2020).
22. Statistics South Africa. Mid-year population estimates 2019. Statistical release P0302. https://www.statssa.gov.za/ publications/P0302/P03022019.pdf (accessed 31 March 2020).

23. Brennan AT, Jamieson L, Crowther NJ, et al. Prevalence, incidence, predictors, treatment, and control of hypertension among HIV-positive adults on antiretroviral treatment in public sector treatment programs in South Africa. PLoS ONE 2018;13(10):e0204020. https://doi.org/10.1371/journal. pone. 0204020

24. Xavier Gómez-Olivé F, Ali SA, Made F, et al. Regional and sex differences in the prevalence and awareness of hypertension differences in the prevalence and awareness of hypertension
across six sites in sub-Saharan Africa: An H3Africa AWI-Gen across six sites in sub-Saharan Africa: An H3Africa AWI-Gen
study. Glob Heart 2017;12(2):81-90. https://doi.org/10.1016/j. gheart.2017.01.007

25. Opie LH, Seedat YK. Hypertension in sub-Saharan African Opie LH, Seedat YK. Hypertension in sub-Saharan African
populations. Circulation 2005;112(23):3562-3568. https://doi rg/10.1161/circulationaho. 105.53956

26. Addo J, Smeeth L, Leon DA. Hypertension in sub-Saharan Africa: A systematic review. Hypertension 2007;50:1012-1018 https://doi.org/10.1161/hypertensionaha.107.093336

27. Ntuli ST, Maimela E, Alberts M, Choma S, Dikope S. Prevalence and associated risk factors of hypertension amongst adults in a rural community of Limpopo Province, South Africa. Afr J Prin Health Care Fam Med 2015;7(1):a847. https://doi.org/10.4102/ phcfm.v7i1.847

28. Salako BL, Ogah OS, Adebiyi AA, et al. Unexpectedly high prevalence of target-organ damage in newly diagnosed Zn S, Hey held A, Heshka S. Race-ethnicity-specific waist circumference cutoffs for identifying cardiovascular disease risk factors. Am J Clin
Nutr 2005;81(2):409-415. https://doi.org/10.1093/ajcn.81.2.409

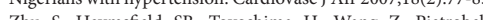

30. Harris MM, Stevens J, Thomas N, Schreiner P, Folsom AR. Associations of fat distribution and obesity with hypertension in a bi-ethnic population: The ARIC study. Atherosclerosis Risk in Communities Study. Obes Res 2000;8(7):516-524. https://doi. in Communities Study. O

31. Neter JE, Stam BE, Kok FJ, Grobbee DE, Geleijnse JM. Influence of weight reduction on blood pressure: A meta-analysis of randomised controlled trials. Hypertension 2003;42(5):878-884 https://doi.org/10.1161/01.HYP.0000094221.86888.AE

32. Majane OH, Norton GR, Maseko MJ, et al. The association of waist circumference with ambulatory blood pressure is independent of alternative adiposity indices. Hypertens 2007;25(9):1798-1806. https://doi.org/10.1097/ HJH.0b013e3281e6666f

33. Stewart S, Libhaber E, Carrington M, et al. The clinical consequences and challenges of hypertension in urban-dwelling black Africans: Insights from the Heart of Soweto Study. Int J Cardiol 2011;146(1):22-27. https://doi.org/10.1016/j. ijcard.2009.05.061

34. Puoane T, Steyn K, Bradshaw D, Laubscher R. Obesity in South Africa: The SA demographic and health survey. Obes Res 2002;10(10):1038-1048. https://doi.org/10.1038/oby.2002.141

35. Al-Goblan AS, Al-Alfi MA, Khan MZ. Mechanism linking diabetes mellitus and obesity. Diabetes Metab Syndr Obe 2014;7:587-591. https://doi.org/10.2147/dmso.s67400

6. World Health Organization. The Global Burden of Disease 2004: Update. Geneva: WHO, 2008. https://apps.who.int/ iris/bitstream/handle/10665/43942/9789241563710_eng.pdi (accessed 8 April 2020).

37. Groenewald P, Bradshaw D, Daniels J, et al. Cause of Death and Premature Mortality in Cape Town, 2001 - 2006. Cape Town: SAMRC, 2008. https://doi.org/10.2471/BLT.09.069435

38. Abegunde DO, Mathers CD, Adam T, Ortegon M, Strong K Burden and costs of chronic disease in low-income and middleincome countries. Lancet 2007;370(9603):1929-1938. https:// income countries. Lancet 2007;370(960):

39. Kenge AP, Mchiza ZJ. Cardiovascular diseases and diabetes mellitus as economic and development challenges in Africa. Prog Cardiovasc Dis 2013;56(3):302-313. https://doi org/10.1016/j.pcad.2013.10.01

40. Mayosi BM, Flisher AJ, Lalloo UG, Sitas F, Tollman SM, Bradshaw D. The burden of non-communicable diseases in South Africa. Lancet 2009;374(9693):934-947. https://doi. org $/ 10.1016 /$ S0140-6736(09)61087-4

41. Pillay-van Wyk V, Msemburi W, Laubscher R, et al. Mortality trends and differentials in South Africa from 1997 to 2012: Second National Burden of Disease Study Lancet Glob Health 2016:4(9):e642-e653, https://doi.org/10.1016/S2214109X(16)30113-9

42. Pillay S, Lutge E, Aldous C. The burden of diabetes mellitus in KwaZulu-Natal's public sector: A 5-year perspective. S Afr Med J 2016;106(4):384-388. https://doi.org/10.7196/SAMI.2016 v106i4.9920

Accepted 7 July 2020 